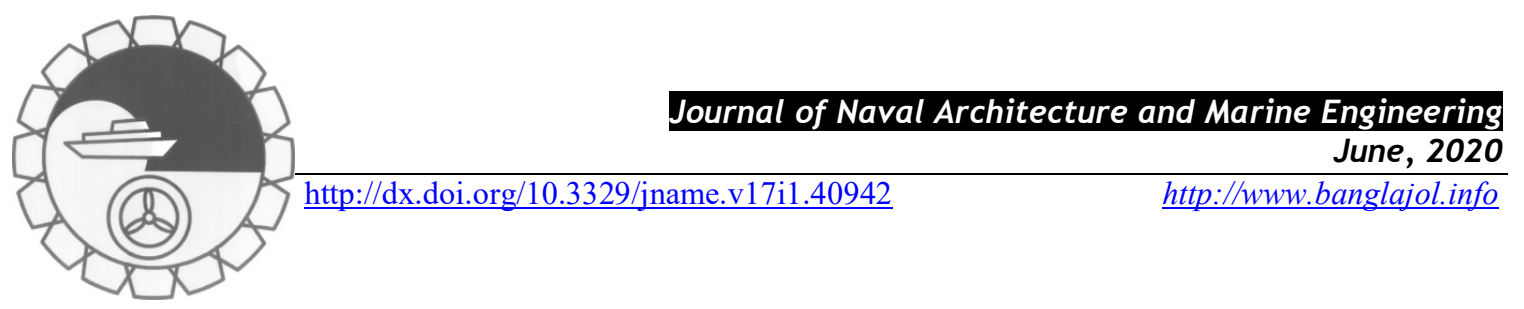

\title{
FLOW OF NON-NEWTONIAN FLUID THROUGH A PERMEABLE ARTERY HAVING NON-UNIFORM CROSS SECTION WITH MULTIPLE STENOSIS
}

\author{
K. Maruthi Prasad ${ }^{1}$, Prabhaker Reddy Yasa $^{2}$
}

${ }^{1}$ Department of Mathematics, School of Science, GITAM (Deemed to be University), Hyderabad, Telangana State, India 502329.Email: kaipa maruthi@yahoo.com

${ }^{2}$ Research Scholar at GITAM (Deemed to be University), Department of BS\&H, B V Raju Institute of Technology (BVRIT), Narsapur, Telangana State, India- 502313. Email: prabhakerreddy.yasa@gmail.com

\begin{abstract}
:
In this paper, the effect of slip on Micropolar fluid in a circular tube of non-uniform cross-section with multiple stenosis have been studied. The coupled equations governing to the flow are calculated by using Homotopy Perturbation Method. The effects of various parameters with heights of the stenosis on the resistance to the flow and wall shear stress have been studied by deriving the expressions for the flow characteristics and their solutions have been obtained.It is found that the resistance to the flow increases with the heights of the stenosis, inclination, Thermophoresis parameter, local temperature Grashof number, local nanoparticle Grashof number, inclination and permeability constant and decreases with Brownian motion parameter. It is found that the shear stress at the wall increases with heights of the stenosis, Brownian motion parameter but decreases with local nanoparticle Grashof number, Thermophoresis parameter and permeability constant
\end{abstract}

Keywords: Resistance to the flow, stenosis, micropolar fluid, couple stress fluid parameters, permeability constant, wall shear stress.

NOMENCLATURE
$\begin{array}{cl}L_{1}, L_{2} & \text { Lengths of the Stenosis } \\ \delta_{1}, \delta_{2} & \text { Heights of the Stenosis } \\ B & \text { Length of the tube } \\ p & \text { Pressure } \\ q & \text { Flow flux } \\ R_{0} & \text { Radius of the tube without stenosis } \\ R & \text { Radius of the tube with stenosis } \\ w & \text { Axial velocity } \\ \Delta p & \text { Pressure drop } \\ \lambda & \text { Resistance to the flow }\end{array}$

$\begin{array}{ll}\text { Greek symbols } \\ \bar{\lambda} & \text { Normalized resistance to the flow } \\ \tau_{h} & \text { Wall shear stress } \\ N_{t} & \text { Thermophoresis parameter } \\ N_{b} & \text { Brownian motion number } \\ B_{r} & \text { Local nanoparticle Grashof number } \\ G_{r} & \text { Local temperature Grashof number } \\ k & \text { Permeability constant } \\ \theta_{t} & \text { Temperature Profile } \\ \sigma & \text { Nanoparticle Phenomena }\end{array}$

\section{Introduction}

Stenosis is the most common valvular heart diseases in the developed countries of the world. Vascular fluid dynamics play an important role in the development of arterial stenosis, which is one of the most extensive diseases in human being resulting to failure of the cardiovascular system. The circulation of blood gets interrupted to an extent depending upon the severity of the stenosis.

Prasad et al. (2010) and Prasad et al. (2015) have studied the peristaltic transport of nanoparticles of micropolar fluid in an inclined tube with heat and mass transport effect. Many researchers have done their work using noslip boundary condition at the walls of the vessels. But the walls are permeable in physiological systems.
Received on: April 2019 
In the past, many researchers assumed the flowing blood to be Newtonian. This assumption of Newtonian behaviour of blood is acceptable for high shear rate flow. But, in some conditions, blood exhibits NonNewtonian properties (Young, 1968, Shukla et al., 1979, Padmanabhan, 1980, Hayat et al., 2008, Ranadhiret al., 2014 and Mandal, 2015). Most of these theoretical models studied the blood flow in a circular tube or channel having single stenosis. But in the reality, there is a possibility of forming multiple stenoses or over lapping Stenoses in the arteries. Notable researchers like Prasad et al. (2008), Muthu et al. (2008), Akbar et al. (2011), Awgichew et al. (2013), Akbar et al. (2013) and Raja et al. (2016)investigated blood flow in arteries with multiple stenosis. In all these studies they considered the wall of the tube is not flexible. He (1999) and He (2005) discussed the Homotopy perturbation technique and its applications.

The present paper considered micropolar fluid in an inclined permeable tube having non-uniform cross-section with two stenosis and investigated the effects of different parameters on pressure drop, resistance to the flow and wall shear stress.

\section{Mathematical Formulation}

Consider the steady flow of micropolar fluid through a circular tube of non-uniform cross section and two stenoses. A cylindrical polar coordinate system $(r, \theta, z)$ is taken so that $z$-axis coincides with the centre line of the tube. It is assumed that the tube is inclined at an angle ' $\alpha$ ' to the horizontal axis [Fig. 1].

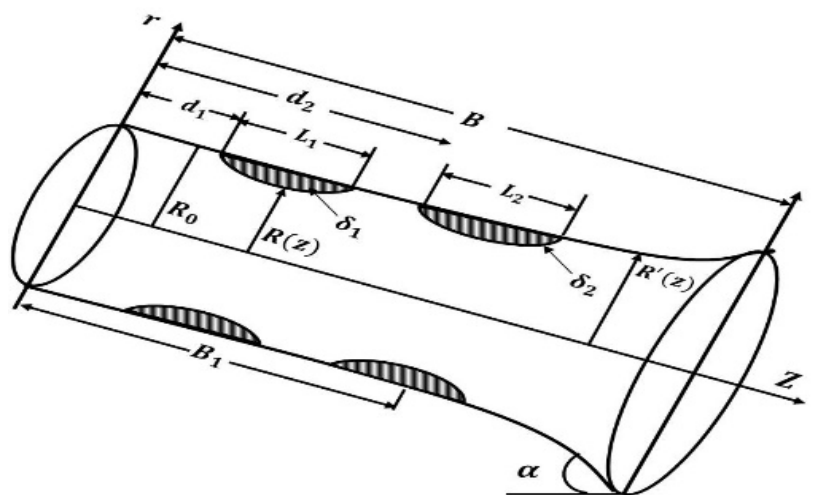

Fig.1: Geometry of an inclined tube with multiple stenoses

Assuming the stenoses are mild and develop in an axially symmetric manner. The radius of the cylindrical tube is taken as (Prasad et al., (2015))

$$
h=R(z)= \begin{cases}R_{0} & : 0 \leq z \leq d_{1}, \\ R_{0}-\frac{\delta_{1}}{2}\left(1+\cos \frac{2 \pi}{L_{1}}\left(z-d_{1}-\frac{L_{1}}{2}\right)\right) & : d_{1} \leq z \leq d_{1}+L_{1}, \\ R_{0}-\frac{\delta_{2}}{2}\left(1+\cos \frac{2 \pi}{L_{2}}\left(z-B_{1}\right)\right) & : d_{1}+L_{1} \leq z \leq B_{1}-\frac{L_{2}}{2}, \\ R_{0}-\frac{L_{2}}{2} \leq z \leq B_{1} \\ R^{*}(z)-\frac{\delta_{2}}{2}\left(1+\cos \frac{2 \pi}{L_{2}}\left(z-B_{1}\right)\right) & : B_{1} \leq z \leq B_{1}+\frac{L_{2}}{2}, \\ R^{*}(z) & : B_{1}+\frac{L_{2}}{2} \leq z \leq B .\end{cases}
$$

The following restrictions for mild stenoses are supposed to satisfy:

$$
\delta_{i} \ll \min \left(R_{0}, R_{\text {out }}\right), \delta_{i} \ll L_{i} \text { where } R_{\text {out }}=R(z) \text { at } z=B .
$$

Flow of non-Newtonian fluid through a permeable artery having non-uniform cross section with multiple stenosis 
Here $L_{i}$ and $\delta_{i}(i=1,2)$ are the lengths and maximum heights of two stenoses (the suffixes 1 and 2 refer to the first and second stenosis respectively).

The equations for an incompressible fluid with mild stenosis are defined as

$\frac{\partial P}{\partial r}=-\frac{\cos \alpha}{F}$

$\frac{N}{r} \frac{\partial}{\partial r}\left(r v_{\theta}\right)+\frac{\partial^{2} w}{\partial r^{2}}+\frac{1}{r} \frac{\partial w}{\partial r}+(1-N) \frac{\sin \alpha}{F}+(1-N)\left(G_{r} \theta_{t}+B_{r} \sigma\right)=(1-N) \frac{\partial P}{\partial z}$

$2 v_{\theta}+\frac{\partial w}{\partial r}-\frac{2-N}{m^{2}} \frac{\partial}{\partial r}\left(\frac{1}{r} \frac{\partial}{\partial r}\left(r v_{\theta}\right)\right)=0$

$\frac{1}{r} \frac{\partial}{\partial r}\left(r \frac{\partial \theta_{t}}{\partial r}\right)+N_{b} \frac{\partial \sigma}{\partial r} \frac{\partial \theta_{t}}{\partial r}+N_{t}\left(\frac{\partial \theta_{t}}{\partial r}\right)^{2}=0$,

$\frac{1}{r} \frac{\partial}{\partial r}\left(r \frac{\partial \sigma}{\partial r}\right)+\frac{N_{t}}{N_{b}}\left(\frac{1}{r} \frac{\partial}{\partial r}\left(r \frac{\partial \theta_{t}}{\partial r}\right)\right)=0$,

where $w$ is the velocity in the axial direction. $\theta_{t}, \sigma, N_{b}, N_{t}, G_{r}$ and $B_{r}$ are temperature profile, nanoparticlephenomena, Brownian motion parameter, thermophoresis parameter, local temperature Grashof number and local nanoparticle Grashof number.

The non-dimensional boundary conditions are

$$
\left.\begin{array}{l}
\frac{\partial w}{\partial r}=0, \frac{\partial \theta_{t}}{\partial r}=0, \frac{\partial \sigma}{\partial r}=0 \text { at } r=0, \\
w=-k \frac{\partial w}{\partial r}, \theta_{t}=0, \sigma=0 \text { at } r=h(z)
\end{array}\right\}
$$

$v_{\theta}$ is finite, $w$ is finite at $r=0$

\section{Solution}

The solutions of the coupled Eq. (4) and (5) have been solved by using Homotopy Perturbation Method (HPM) as

$H\left(q_{t}, \theta_{t}\right)=\left(1-q_{t}\right)\left[L\left(\theta_{t}\right)-L\left(\theta_{10}\right)\right]+q_{t}\left[L\left(\theta_{t}\right)+N_{b} \frac{\partial \sigma}{\partial r} \frac{\partial \theta_{t}}{\partial r}+N_{t}\left(\frac{\partial \theta_{t}}{\partial r}\right)^{2}\right]$

$H\left(q_{t}, \sigma\right)=\left(1-q_{t}\right)\left[L(\sigma)-L\left(\sigma_{10}\right)\right]+q_{t}\left[L(\sigma)+\frac{N_{t}}{N_{b}}\left(\frac{1}{r} \frac{\partial}{\partial r}\left(r \frac{\partial \theta_{t}}{\partial r}\right)\right)\right]$,

Where $q_{t}$ is the embedding parameter which has the range $0 \leq q_{t} \leq 1$. For our convenience,

$L=\frac{1}{r} \frac{\partial}{\partial r}\left(r \frac{\partial}{\partial r}\right)$ is taken as a linear operator. The initial guesses $\theta_{10}$ and $\sigma_{10}$ are defined as

$\theta_{10}(r, z)=\left(\frac{r^{2}-h^{2}}{4}\right), \sigma_{10}(r, z)=-\left(\frac{r^{2}-h^{2}}{4}\right)$

$\theta_{t}(r, z)=\theta_{t_{0}}+q_{t} \theta_{t_{1}}+q_{t}^{2} \theta_{t_{2}}+\ldots$

$\sigma(r, z)=\sigma_{0}+q_{t} \sigma_{1}+q_{t}^{2} \sigma_{2}+\ldots$

The series (10) and (11) are convergent for most of the cases. The convergent depends on the nonlinear part of the equation. Adopting the same procedure as done by Prasadet al.(2015), the solution for temperature and nanoparticle phenomena can be written for $q_{t}=1$ as

$$
\begin{aligned}
& \theta_{t}(r, z)=\left(\frac{r^{2}-h^{2}}{64}\right)\left(N_{b}-N_{t}\right) \\
& \sigma(r, z)=-\left(\frac{r^{2}-h^{2}}{4}\right) \frac{N_{t}}{N_{b}} .
\end{aligned}
$$

Substituting the Eq. (12) and (13) in Eq. (5) and applying boundary conditions, the exact solution for the velocity will be

$$
\begin{gathered}
w(r, z)=(1-N)\left(\frac{r^{2}-h^{2}}{4}-\frac{k r}{2}\right)\left(-\frac{\sin \alpha}{F}+\frac{d P}{d z}\right)-N(r-h-k) v_{\theta}+(1-N) B_{r} \frac{N_{t}}{N_{b}}\left(\frac{r^{4}}{64}-\frac{r^{2} h^{2}}{16}+\frac{3 h^{4}}{64}-\frac{k r^{3}}{16}+\right. \\
\left.\frac{k r h^{2}}{8}\right)-(1-N) G_{r}\left(N_{b}-N_{t}\right)\left(\frac{r^{6}}{2304}-\frac{r^{2} h^{4}}{256}+\frac{h^{6}}{288}-\frac{k r^{5}}{384}+\frac{k r h^{4}}{128}\right)
\end{gathered}
$$


The dimension less flux $q$ can be calculated as $q=\int_{0}^{h} 2 r w d r$.

By substituting the Eq. (13) in (14), the flux is given by

$$
\begin{gathered}
q=(1-N)\left(\frac{h^{4}}{8}+\frac{k h^{3}}{3}\right)\left(\frac{\sin \alpha}{F}-\frac{d P}{d z}\right)+N\left(h^{3}+k h^{2}\right) v_{\theta}+(1-N) B_{r} \frac{N_{t}}{N_{b}}\left(h^{6}(0.02083)+k h^{5}(0.05833)\right)- \\
(1-N) G_{r}\left(N_{b}-N_{t}\right)\left(h^{8}(0.001627)+k h^{7}(0.004464)\right)
\end{gathered}
$$

From the above equation, $\frac{d P}{d z}$ can be given as

$\frac{d P}{d z}=$

$\frac{1}{\left(\frac{h^{4}}{8}+\frac{k h^{3}}{3}\right)}\left[-\frac{q}{1-N}+\left(\frac{h^{4}}{8}+\frac{k h^{3}}{3}\right) \frac{\sin \alpha}{F}+\frac{N}{1-N}\left(h^{3}+k h^{2}\right) v_{\theta}-G_{r}\left(N_{b}-N_{t}\right)\left(h^{8}(0.001627)+k h^{7}(0.004464)\right)+\right.$

$\left.B_{r} \frac{N_{t}}{N_{b}}\left(h^{6}(0.02083)+k h^{5}(0.05833)\right)\right]$

The pressure drop per wave length $\Delta p=p(0)-p(\lambda)$ is

$$
\begin{gathered}
\Delta p=-\int_{0}^{1} \frac{d P}{d z} d z \\
=\int_{0}^{1} \frac{1}{\left(\frac{h^{4}}{8}+\frac{k h^{3}}{3}\right)}\left[\frac{q}{1-N}-\left(\frac{h^{4}}{8}+\frac{k h^{3}}{3}\right) \frac{\sin \alpha}{F}-\frac{N}{1-N}\left(h^{3}+k h^{2}\right) v_{\theta}+G_{r}\left(N_{b}-N_{t}\right)\left(h^{8}(0.001627)+\right.\right. \\
\left.\left.k h^{7}(0.004464)\right)-B_{r} \frac{N_{t}}{N_{b}}\left(h^{6}(0.02083)+k h^{5}(0.05833)\right)\right] d z
\end{gathered}
$$

The resistance to the flow $\lambda$ is defined as

$$
\begin{aligned}
\lambda= & \frac{\Delta p}{q} \\
= & \frac{1}{q} \int_{0}^{1} \frac{1}{\left(\frac{h^{4}}{8}+\frac{k h^{3}}{3}\right)}\left[\frac{q}{1-N}-\left(\frac{h^{4}}{8}+\frac{k h^{3}}{3}\right) \frac{\sin \alpha}{F}-\frac{N}{1-N}\left(h^{3}+k h^{2}\right) v_{\theta}+G_{r}\left(N_{b}-N_{t}\right)\left(h^{8}(0.001627)+\right.\right. \\
& \left.\left.k h^{7}(0.004464)\right)-B_{r} \frac{N_{t}}{N_{b}}\left(h^{6}(0.02083)+k h^{5}(0.05833)\right)\right] d z
\end{aligned}
$$

The pressure drop in the absence of stenosis $h=1$ is denoted by $\Delta p_{n}$ and is obtained from Eq. (18) as

$$
\begin{aligned}
\Delta p_{n}= & \int_{0}^{1} \frac{1}{\left(\frac{1}{8}+\frac{k}{3}\right)}\left[\frac{q}{1-N}-\left(\frac{1}{8}+\frac{k}{3}\right) \frac{\sin \alpha}{F}-\frac{N}{1-N}\left(h^{3}+k h^{2}\right) v_{\theta}+G_{r}\left(N_{b}-N_{t}\right)((0.001627)+k(0.004464))-\right. \\
& \left.B_{r} \frac{N_{t}}{N_{b}}((0.02083)+k(0.05833))\right] d z
\end{aligned}
$$

The resistance to the flow in the normal artery is denoted by

$$
\begin{aligned}
\lambda_{n}= & \frac{\Delta p_{n}}{q} \\
= & \frac{1}{q} \int_{0}^{1} \frac{1}{\left(\frac{1}{8}+\frac{k}{3}\right)}\left[\frac{q}{1-N}-\left(\frac{1}{8}+\frac{k}{3}\right) \frac{\sin \alpha}{F}-\frac{N}{1-N}(1+k) v_{\theta}+G_{r}\left(N_{b}-N_{t}\right)((0.001627)+k(0.004464))-\right. \\
& \left.\quad B_{r} \frac{N_{t}}{N_{b}}((0.02083)+k(0.05833))\right] d z
\end{aligned}
$$

The normalized resistance to the flow denoted by

$$
\bar{\lambda}=\frac{\lambda}{\lambda_{n}}
$$

And the wall shear stress is

$$
\tau_{h}=-\frac{h}{2} \frac{d P}{d z}
$$




$$
\begin{aligned}
= & \frac{h}{2}\left[\frac { 1 } { ( \frac { h ^ { 4 } } { 8 } + \frac { k h ^ { 3 } } { 3 } ) } \left[\frac{q}{1-N}-\left(\frac{h^{4}}{8}+\frac{k h^{3}}{3}\right) \frac{\sin \alpha}{F}-\frac{N}{1-N}\left(h^{3}+k h^{2}\right) v_{\theta}-G_{r}\left(N_{b}-N_{t}\right)\left(h^{8}(0.001627)+\right.\right.\right. \\
& \left.\left.\left.k h^{7}(0.004464)\right)+B_{r} \frac{N_{t}}{N_{b}}\left(h^{6}(0.02083)+k h^{5}(0.05833)\right)\right]\right]
\end{aligned}
$$

\section{Result and Discussion}

The expressions for pressure $\operatorname{drop}(\Delta p)$, resistance to the flow $(\bar{\lambda})$, and wall shear stress $\left(\tau_{h}\right)$ are given by the Eq. (18), Eq. (22) and Eq. (23) respectively. Using Mathematica 9.1, the effects of various parameters on pressure $\operatorname{drop}(\Delta p)$, resistance to the flow $(\bar{\lambda})$, and wall shear stress $\left(\tau_{h}\right)$ with nanoparticle phenomena have been calculated numerically, by taking

$$
\frac{R^{*}(z)}{R_{0}}=\exp \left[\beta B^{2}\left(z-B_{1}\right)^{2}\right], \text { Where } d_{1}=0.2, L_{1}=L_{2}=0.2, B_{1}=0.7, B=1 \text { and } \beta=0.01 \text {. }
$$

The effects of various parameters on the resistance to the flow $(\bar{\lambda})$ are shown in Figures (2-8) for various values of Brownian motion number $\left(N_{b}\right)$, thermophoresis parameter $\left(N_{t}\right)$, local temperature Grashof number $\left(G_{r}\right)$, local nanoparticle Grashof number $\left(B_{r}\right)$, inclination $(\alpha)$. It is observed that, the resistance to the flow $(\bar{\lambda})$ increases with the heights of the stenosis $\left(\delta_{1}\right.$ and $\left.\delta_{2}\right)$, local temperature Grashof number $\left(G_{r}\right)$, local nanoparticle Grashof number $\left(B_{r}\right)$ and inclination $(\alpha)$. It is noted that, the velocity of the particles with the surrounding molecules $\left(N_{t}\right)$ increases with the increases of heights of the stenosis. It is remarkable to note that, the permeability $(k)$ of the walls of the artery increases with the increase of Resistance to the flow.

It is interesting to note that, the resistance to the flow decreases with the increase of the collision between the molecules. I.e., Brownian motion parameter $\left(N_{b}\right)$.

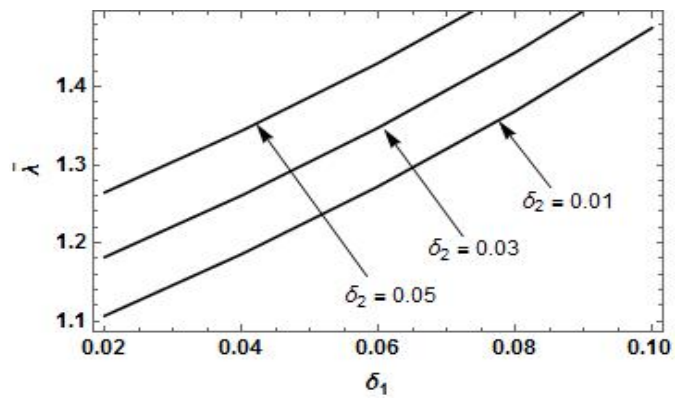

Fig. 2: Effect of heights of stenosis $\delta_{1}$ on the Resistance to the flow $\bar{\lambda}$, with $\delta_{2}$ varying $\left(q=0.3, F=0.3, B_{r}=0.3, G_{r}=0.2, N_{b}=\right.$ $\left.0.3, N_{t}=0.8, \alpha=\frac{\pi}{6}, k=0.05\right)$

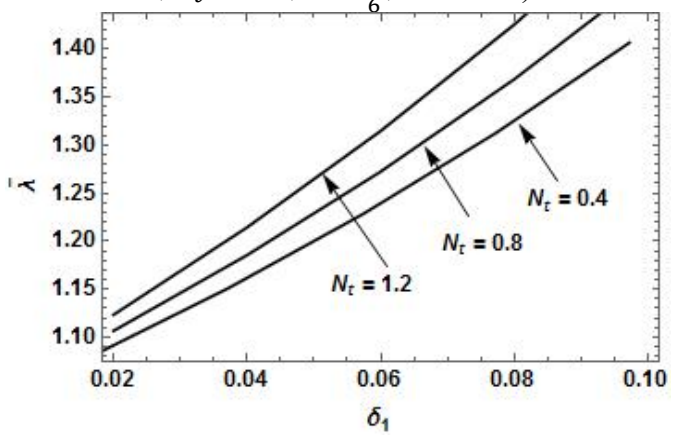

Fig. 4: Effect of heights of stenosis $\delta_{1}$ on the Resistance to the flow $\bar{\lambda}$, with $N_{t}$ varying $\left(q=0.3, \delta_{2}=0.05, F=0.3, B_{r}=0.3, G_{r}=\right.$ $0.2, N_{b}=0.3, \alpha=\frac{\pi}{6}, k=0.05$ )

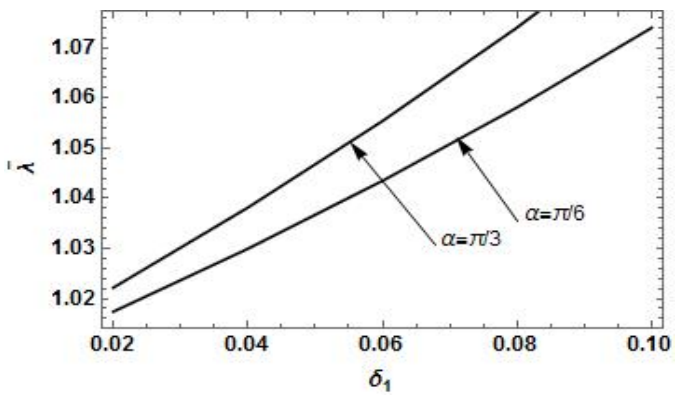

Fig. 3: Effect of heights of stenosis $\delta_{1}$ on the Resistance to the flow $\bar{\lambda}$, with $\alpha$ varying $\left(q=0.3, F=0.3, B_{r}=0.3, G_{r}=0.2, N_{b}=\right.$ $0.3, N_{t}=0.8, \delta_{2}=0.01, k=0.05$ )

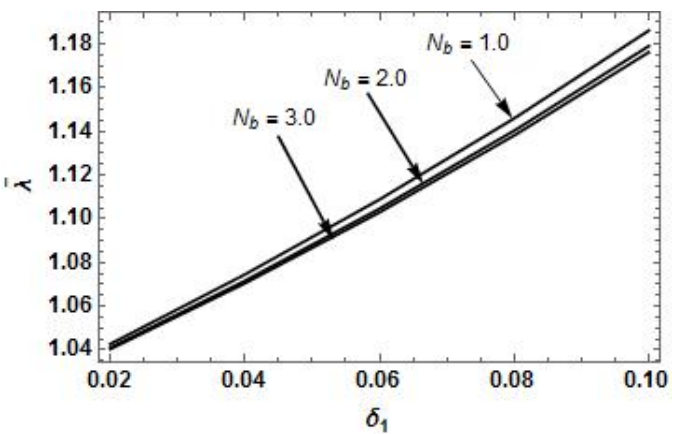

Fig. 5: Effect of heights of stenosis $\delta_{1}$ on the Resistance to the flow $\bar{\lambda}$, with $N_{b}$ varying $\left(q=0.3, \delta_{2}=0.05, F=0.3, B_{r}=0.3, G_{r}=\right.$ $0.2, N_{t}=0.8, \alpha=\frac{\pi}{6}, k=0.05$ ) 
The shear stress acting on the wall $\left(\tau_{h}\right)$ over the height of stenosis has shown in the Figures (9-13). It is shown that, the shear stress at the wall increases with height of the stenosis. Also, it is observed that when the collision between the molecules $\left(N_{b}\right)$ increases, the shear stress at the wall also increases. It is also noted that, the shear stress at the wall decreases with $\left(B_{r}\right)$, with the heat and mass transfer coefficient $\left(N_{t}\right)$ and permeability constant $(k)$.

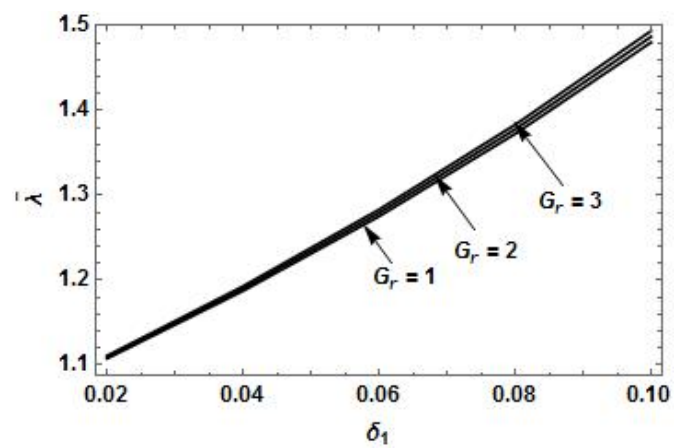

Fig. 6: Effect of heights of stenosis $\delta_{1}$ on the Resistance to the flow $\bar{\lambda}$, with $G_{r}$ varying $\left(q=0.3, \delta_{2}=\right.$ $0.05, F=0.3, B_{r}=0.3, N_{t}=0.8, N_{b}=0.3, \alpha=$

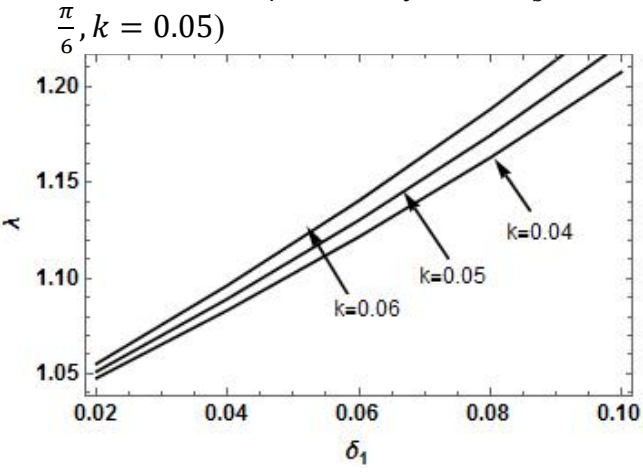

Fig. 8: Effect of heights of stenosis $\delta_{1}$ on the Resistance to the flow $\bar{\lambda}$, with $k$ varying $\left(q=0.3, \delta_{2}=\right.$ $0.05, F=0.3, G_{r}=0.2, B_{r}=0.3, N_{t}=$ $\left.0.8, N_{b}=0.3, \alpha=\frac{\pi}{6}\right)$

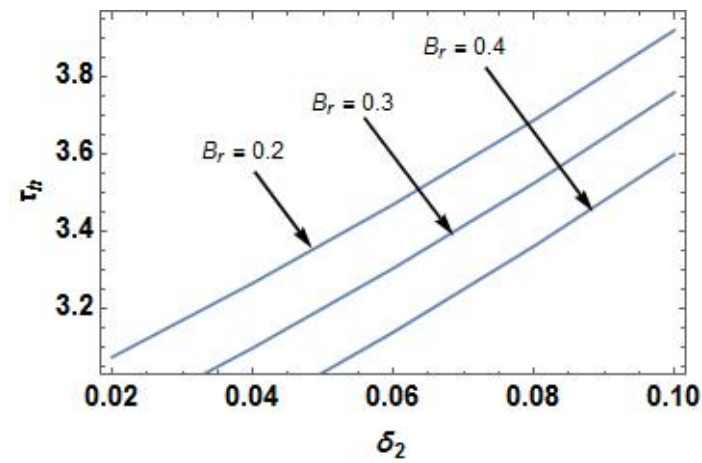

Fig.10: Effect of heights of stenosis $\delta_{2}$ on wall shear stress $\tau_{h}$, with $B_{r}$ varying $\left(q=0.3, \delta_{1}=\right.$ $0.1, F=0.3, G_{r}=0.2, N_{t}=0.3, N_{b}=$ $0.1, \alpha=\frac{\pi}{6}, k=0.05$ )

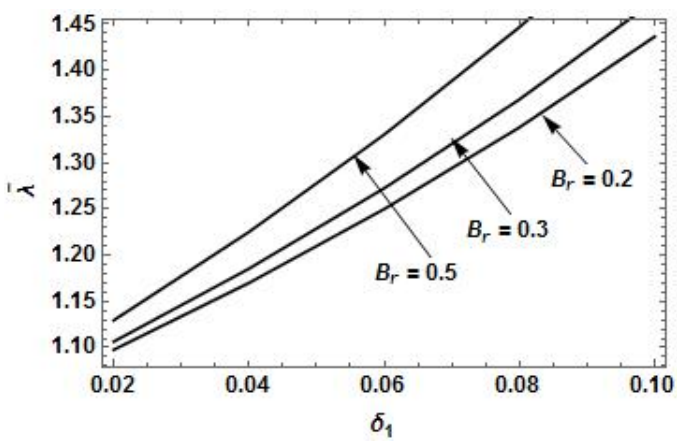

Fig. 7: Effect of heights of stenosis $\delta_{1}$ on the Resistance to the flow $\bar{\lambda}$, with $B_{r} \operatorname{varying}(q=$ $0.3, \delta_{2}=0.05, F=0.3, G_{r}=0.2, N_{t}=$ $0.8, N_{b}=0.3, \alpha=\frac{\pi}{6}, k=0.05$ )

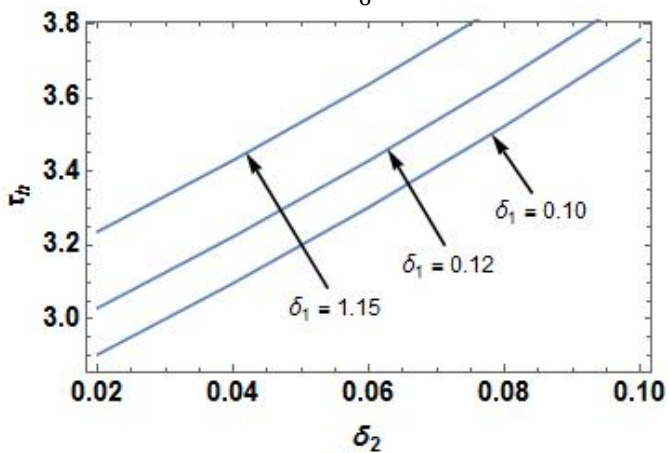

Fig.9: Effect of heights of stenosis $\delta_{2}$ on wall shear stress $\tau_{h}$, with $\delta_{1} \quad \operatorname{varying}(q=0.3, F=$ $0.3, G_{r}=0.2, B_{r}=0.3, N_{t}=0.3, N_{b}=$ $0.1, \alpha=\frac{\pi}{6}, k=0.05$ )

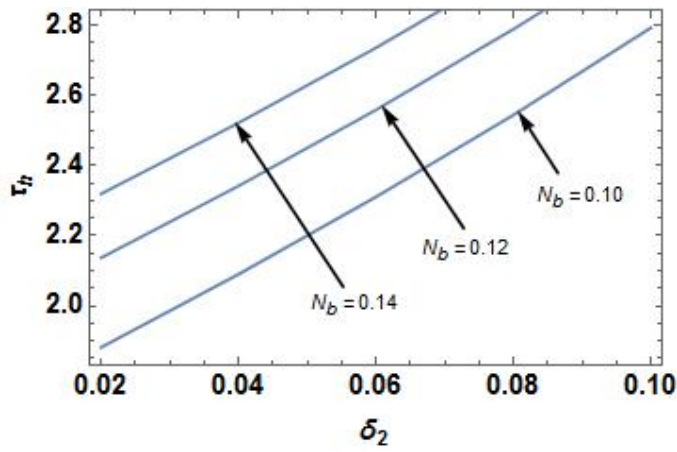

Fig.11: Effect of heights of stenosis $\delta_{2}$ on wall shear stress $\tau_{h}$, with $N_{b} \quad \operatorname{varying}\left(q=0.3, \delta_{1}=\right.$ $0.1, F=0.3, G_{r}=0.2, B_{r}=0.3, N_{t}=0.3, \alpha=$ $\frac{\pi}{6}, k=0.05$ ) 


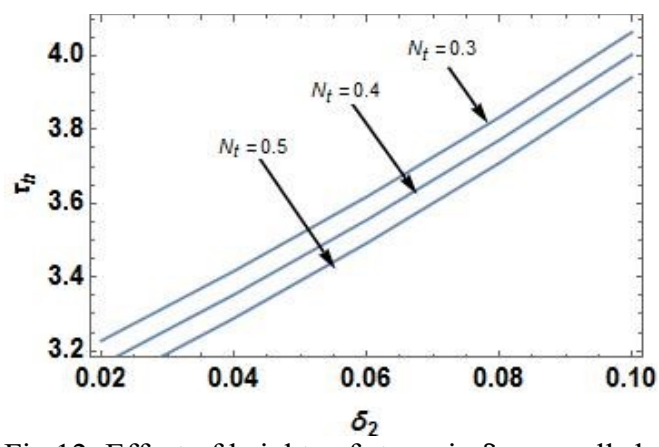

Fig.12: Effect of heights of stenosis $\delta_{2}$ on wall shear stress $\tau_{h}$, with $N_{t}$ varying ( $q=0.3, \delta_{1}=$ $0.1, F=0.3, G_{r}=0.2, B_{r}=0.3, N_{b}=$ $\left.0.1, \alpha=\frac{\pi}{6}, k=0.05\right)$

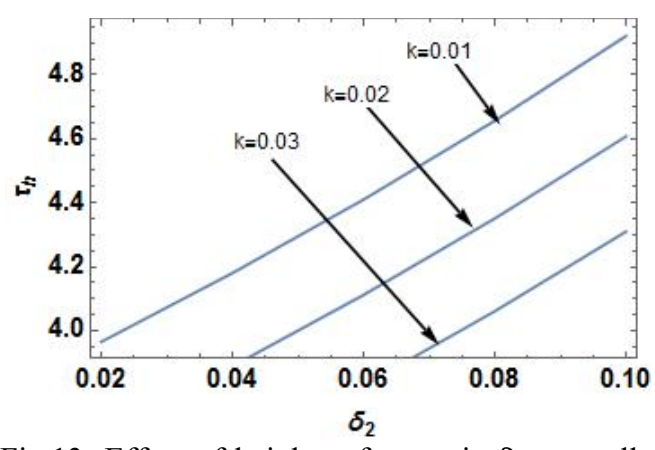

Fig.13: Effect of heights of stenosis $\delta_{2}$ on wall shear stress $\tau_{h}$, with $k$ varying $\left(q=0.3, \delta_{1}=\right.$ $0.1, F=0.3, G_{r}=0.2, B_{r}=0.3, N_{b}=$ $\left.0.1, \alpha=\frac{\pi}{6}, N_{t}=0.3\right)$

\section{Conclusion}

A Mathematical model for steady flow of Micro-polar fluid through permeable tube of varying cross-section and is having two stenosis has been studied.The solutions for resistance to the flow, wall shear stress were obtained by using Homotopy Perturbation method.

The conclusions of this model are

1. The resistance to the flow increases with the heights of stenosis, inclination, Thermophoresis parameter, Local temperature Grashof number, local nanoparticle Grashof number, permeability constant, and decreases with Brownian motion parameter.

2. It is interesting to note that, the resistance to the flow decreases with the heights of the stenosis $\left(\delta_{1}\right)$ with Brownian motion parameter. But this decrease is significant only when height of the first stenosis exceeds the value 0.04 .

3. It is also observed that the resistant to the flow increases with heights of stenosis with local temperature Grashof number, but this increase is significant after the value of the first stenosis exceeds 0.08 .

4. As heights of the stenosis increases, the wall shear stress increases and it is also observed that the collision between the molecules increases with the shear stress at wall.

5. The wall shear stress decreases with local nanoparticle Grashof number, Thermophoresis parameter and Permeability constant.

\section{References}

Akbar, N. S., Nadeem, S., Hayat, T., and Hendi, A.A. (2011): Peristaltic flow of a Nanofluid in a non-uniform tube, Heat and Mass Transfer, Vol. 48, No. 3, pp. 451-59. https://link.springer.com/article/10.1007/s00231-0110892-7

Akbar, N. S., and Nadeem, S. (2013): Peristaltic flow of a micropolar fluid with nanoparticles in small intestine, Applied Nanoscience, Vol. 3, No. 6, pp. 461-68 .https://link.springer.com/article/10.1007/s13204-012-0160-2

Awgichew, G., and Radhakrishnamacharya, G. (2013): Effect of slip condition and multiple constructions on couple stress fluid flow through a channel of non-uniform cross section, ARPN Journal of Engineering and Applied Sciences, Vol. 8, No. 5. http://connection.ebscohost.com/c/articles/89165695

Hayat, T., and Ali, N. (2008): Effects of an endoscope on peristaltic flow of a micropolar fluid,Mathematical and Computer Modelling,Vol. 48, No.5-6, pp. 721-33. https://doi.org/10.1016/j.mcm.2007.11.004

He, J. H. (1999): Homotopy perturbation technique, Computer Methods in Applied Mechanics and Engineering, Vol. 178, No. 3-4, pp. 257-62. https://doi.org/10.1016/S0096-3003(01)00312-5

He, J. H. (2005): Application of homotopy perturbation method to nonlinear wave equations, Chaos, Solitons\& Fractals, Vol. 26, No. 3, pp. 695-700. https://doi.org/10.1016/j.chaos.2005.03.006 
Mandal, P. K. (2015): An unsteady analysis of non-Newtonian blood flow through tapered arteries with stenosis, International Journal of Non-Linear Mechanics, Vol. 40, pp. 151-64.

Muthu, P., Kumar, B.V. R., and Chandra, P. (2008): Peristaltic motion of micropolar fluid in circular cylindrical tubes: Effect of wall properties, Applied Mathematical Modelling, Vol. 32, No. 10, pp. 2019-33.

Padmanabhan, N., (1980): Mathematical model of arterial stenosis, Medical and Biological Engineering and Computing, Vol. 18,pp. 281-86. https://doi.org/10.1007/bf02443380

Prasad, K. M., and Radhakrishnamacharya, G. (2008): Flow of Herschel-Buckley fluid through an inclined tube of non-uniform cross-section with multiple stenoses, Archives of Mechanics, Vol.60, No.2, pp. 161-72. http://am.ippt.pan.pl/am/article/view/v60p161

Prasad, K. M., Radhakrishnamacharya, G. and Murthy, J. R. (2010): Peristaltic pumping of a micropolar fluid in an inclined tube, International Journal of Applied Mathematics and Mechanics, Vol. 6, No. 11, pp. 26-40. https://www.researchgate.net/publication/280688291

Prasad, K.M., Subadra, N., and Srinivas, M. A. (2015): Peristaltic transport of nanofluid in an inclined tube, American Journal of Computational and Applied Mathematics, Vol. 5, No. 4, pp.117-28.

https://doi.org/10.5923/j.ajcam.20150504.04

Raja, A., and Varshney, N. K. (2016): Pulsatile flow of Herschel-Buckley fluid through an inclined multiple stenoses artery with periodic body acceleration, Pelagia Research Library, Advances in Applied Science Research, Vol.7, No. 3, pp.102-13.

Randhir, R., Daniel N. R., and Nelson C. (2014):Mathematical modeling of blood flow in an artery with an unsteady stenosis using power-law fluid model, SOP Transactions on Applied Mathematics, Vol. 1, No. 1, pp2373-8480. https://www.scipublish.com/journals/AM/papers/383

Shukla, J. B., Parihar, R. S. and Rao, B. R. P. (1979): Effects of stenosis on non-Newtonian flow of the blood in an artery, Bulletin of Mathematical Biology, Vol. 42, pp. 283-94. https://doi.org/10.1007/BF02460787

Young, D. F. (1968): Effects of time-dependent stenosis on flow through a tube, Journal of Engineering and Industrial Transactions, ASME, Vol. 90,pp.248-54. 